\title{
Interactive comment on "Microstructure
} representation of snow in coupled snowpack and microwave emission models" by Melody Sandells \section{et al.}

Melody Sandells et al.

melody.sandells@coresscience.co.uk

Received and published: 3 November 2016

Please note the response to review comments are included in the supplement

Please also note the supplement to this comment:

http://www.the-cryosphere-discuss.net/tc-2016-181/tc-2016-181-AC2-supplement.pdf 